\title{
Prognostic significance of stem cell/ epithelial-mesenchymal transition markers in periampullary/pancreatic cancers: FGFR1 is a promising prognostic marker
}

Yosep Chong $^{1 *}$ (D), Nishant Thakur ${ }^{1}$, Kwang Yeol Paik ${ }^{2}$, Eun Jung Lee ${ }^{1,3}$ and Chang Suk Kang ${ }^{1,4}$

\begin{abstract}
Background: Periampullary cancers (PAC) including pancreatic, ampulla of Vater (AOV), and common bile duct (CBD) cancers are highly aggressive with a lack of useful prognostic markers beyond T stage. However, T staging can be biased due to the anatomic complexity of this region. Recently, several markers related to cancer stem cells and epithelial-mesenchymal transition (EMT) such as octamer transcription factor-4 (Oct4) and fibroblast growth factor receptor 1 (FGFR1) respectively, have been proposed as new promising markers in other solid cancers. The aim of this study was to assess the expression and prognostic significance of stem cell/EMT markers in PACs.

Methods: Formalin-fixed, paraffin-embedded tissues of surgically excised PACs from the laboratory archives from 1998 to 2014 were evaluated by immunohistochemical staining for stem cell/EMT markers using tissue microarray. The clinicopathologic parameters were documented and statistically analyzed with the immunohistochemical findings. Survival and recurrence data were collected and analyzed.

Results: A total of 126 PAC cases were evaluated. The average age was 63 years, with 76 male and 50 female patient samples. Age less than 74 years, AOV cancers, lower T \& N stage, lower tumor size, no lymphatic, vascular, perineural invasion and histologic well differentiation, intestinal type, no fibrosis, severe inflammation were significantly associated with the better overall survival High expression levels of FGFR1 as well as CK20, CDX2, and VEGF were significantly related to better overall survival, while other stem cell markers were not related. Similar findings were observed for tumor recurrence using disease-free survival.

Conclusions: In addition to other clinicopathologic parameters, severe fibrosis was related to frequent tumor recurrence, and high FGFR1 expression was associated with better overall survival. Histologic changes such as extensive fibrosis need to be investigated further in relation to EMT of PACs.
\end{abstract}

Keywords: Pancreatic ductal carcinoma, Duodenal neoplasms, Common bile duct neoplasm, SOX transcription factor, Duodenal neoplasms, Fibroblast growth factor receptor, Octamer transcription factor-4

\footnotetext{
* Correspondence: ychong@catholic.ac.kr

1 Department of Hospital Pathology, Yeouido St. Mary's Hospital, College of

Medicine, The Catholic University of Korea, 10, 63-ro, Yeongdeungpo-gu,

Seoul 07345 , Republic of Korea

Full list of author information is available at the end of the article
}

(c) The Author(s). 2020 Open Access This article is licensed under a Creative Commons Attribution 4.0 International License, which permits use, sharing, adaptation, distribution and reproduction in any medium or format, as long as you give appropriate credit to the original author(s) and the source, provide a link to the Creative Commons licence, and indicate if changes were made. The images or other third party material in this article are included in the article's Creative Commons licence, unless indicated otherwise in a credit line to the material. If material is not included in the article's Creative Commons licence and your intended use is not permitted by statutory regulation or exceeds the permitted use, you will need to obtain permission directly from the copyright holder. To view a copy of this licence, visit http://creativecommons.org/licenses/by/4.0/ The Creative Commons Public Domain Dedication waiver (http://creativecommons.org/publicdomain/zero/1.0/) applies to the data made available in this article, unless otherwise stated in a credit line to the data. 


\section{Background}

Periampullary cancers (PAC) including pancreatic, ampulla of Vater (AOV), and common bile duct (CBD) cancers are highly aggressive tumors, and their 5-year survival rate is less than 4 , and $90 \%$ of the patients die from the disease within a year after diagnosis [1]. PACs are expected to rank as the second leading cause of cancer death in 10 years after lung cancers [2]. This is presumed to be because of the invasive growth of the tumor, delayed diagnosis due to the absence of specific symptoms, and limited treatment options. To date, the $\mathrm{T}$ stage, which represents the operability of curative resection is the most convincing prognostic marker, according to the American Joint Cancer Committee/Union International Contre le Cancer staging system (AJCC/ UICC) [1]. However, $\mathrm{T}$ stage evaluation completely depends on the pathologist's decision based only on gross and pathologic examination, which can be subjective by individuals due to the anatomical complexity of this region [2].

Moreover, as the tumor grows and invades more than two adjacent tissues, such as duodenum and AOV, or distal CBD and pancreatic head, determining the epicenter of the tumor is not straightforward, and might not produce reproducible results between examiners. In a recent review by Adsay et al., the T stage in 39\% of the examined cases differed from the original reports [2]. Moreover, the $\mathrm{T}$ staging system is different for each cancer, which depends on the primary location (Supplementary Table 1) [3]. For example, a tumor that lies on the distal CBD and AOV with duodenal involvement is T3 for CBD cancer while it is $\mathrm{T} 2$ for AOV cancer according to the AJCC cancer staging 7th edition; There's a higher chance to get the same results by 8 th edition that the CBD tumors with duodenal involvement would likely invade the bile duct wall with a depth greater than $12 \mathrm{~mm}$. According to the official guidelines of AJCC, the survival of patients with $\mathrm{T} 1$ and $\mathrm{T} 2$ stages was reversed during the first year after surgery [3]. Therefore, there is an immediate need for a feasible substitute for proper prognostic anticipation, but thus far, no effective markers have been developed.

Recent studies have found that many solid tumors, such as breast and colon cancers, are composed of heterogeneous tumor clusters showing different molecular genetic characteristics. Cancer stem cells are believed to play a major role in tumor development, progression, metastasis, and resistance. More recently, in pancreatic cancer cell lines, stem cell markers, such as Oct4, NANOG, and SOX2, were found to be aberrantly overexpressed compared to normal pancreatic cell lines [4-6]. This aberrant overexpression resulted in uncontrolled proliferation and dedifferentiation of tumor cells by causing changes in the expression of genes that control the G1/S phase of the cell cycle, and epithelial-mesenchymal transition (EMT) [4, 7-9]. Likewise, several EMT markers such as FGFR1, IGF-1, VEGF, and recently ZEB1/2, SNAIL/ SLUG, are being considered as promising prognostic markers [10, 11]. Moreover, these markers are thought to be very important as potential targets for tailored therapy. However, the expression of these markers and their prognostic significance in clinical cases of PACs have not been fully studied.

The purpose of this study was to assess the expression and prognostic significance of the stem cell markers and the markers related to EMT in PACs, and finally to identify a panel of prognostic markers that can classify PACs into more relevant groups.

\section{Methods}

\section{Patients and samples}

This study was approved by the Institutional Review Board of the Catholic University of Korea (SC14SISI0052). We investigated formalin-fixed, paraffin-embedded tissues of surgically excised PACs from our laboratory archives (Yeouido St. Mary's Hospital, Seoul, Korea) from 1998 to 2014 (15 years). These included pancreatic head cancers, distal CBD cancers, AOV cancers, and duodenal cancers with periampullary involvement, excised by Whipple surgery or pylorus-preserving pancreaticoduodenectomy. None of the cases had undergone any type of preoperative chemotherapy. We sequentially retrieved a total of 126 cases after excluding intraductal papillary mucinous neoplasms, which are considered as benign or premalignant lesions, metastatic cancers from other organs, and duodenal cancers without ampullary or pancreatic involvement. The mean age of the enrolled patient cases was 63 years (ranging from 36 to 82 years), and out of 126 cases, 76 were male, and 50 were female. The retrieved cases were blinded by sequential numbering. The hematoxylin and eosin-stained slides were independently reviewed by two pathologists (Y. Chong and EJ. Lee) to confirm the original diagnosis. The cases with not enough tissue available for tissue microarray analysis were excluded. The epicenter of the tumors was reevaluated and compared with the evaluation from the original diagnosis.

The clinicopathologic data were documented: location of the mass, gross type (fungating/polypoid, sessile, ulceroinfiltrative), presence of ulceration, tumor size (largest diameter), radial resection margin involvement, TNM stage, lymphatic, vascular, perineural invasion, histologic differentiation (pancreaticobiliary vs. intestinal subtype, and well, moderately, poorly for each type), degree of fibrosis and inflammatory cell infiltration (mild, moderate, severe), date of surgery, follow-up duration, date of recurrence, and date of death. The degree of fibrosis was described by the fourth -tier system based on H\&E finding (none $(<10 \%)$, mild $(10-33 \%)$, moderate(34-66\%), and severe $(67-100 \%))$. The epicenter of the tumor was 
reevaluated for each case and compared with the original diagnosis, based on the staging system of AJCC/UICC 7th edition because most of the cases were originally diagnosed based on the 7th edition. T stage was rescored according to the revised tumor epicenter and compared with the original $\mathrm{T}$ stage. Pancreaticobiliary and intestinal subtype was determined based on the results of immunohistochemical staining for CK7, CK20, CDX-2, and MUC2 (Mucin 2),. Information regarding the cause and date of death was collected based on National Death Certificate data and medical records from our institute. Since National Death Certificate records have a year of delay for data collection, the death data of recent cases of 2013 and 2014 were documented according to our institutional medical records. Tumor recurrence was defined as a newly detected tumor or metastasis upon radiological examination such as computed tomography (CT) or position emission tomography (PET-CT) with or without an increase of serum CA19-9 level in the surgically resectable cases. Incompletely resected cases with progressive disease were excluded from assessment for tumor recurrence and, death resulting from early complications such as bleeding, bile leakage, infection, and pulmonary embolism were not considered as cancer-related death. Cases with the unknown or unspecified cause of death were excluded from survival analysis.

\section{Tissue microarray}

Nine TMA recipient blocks were made using QuickRay ${ }^{\circ}$ Tissue Microarray recipient block (UB06-2, UNITMA Co., LTD., Seoul, Korea). Three $2 \mathrm{~mm}$ sized tumor spots representing each case were taken from donor blocks to avoid tissue loss and edge artifact. Each recipient block consisted of 45 cores of tumor tissue (15 cases), and 4 cores of positive controls for stem cell markers, and 1 core of negative control. To reduce tissue loss, the recipient blocks were incubated at $30^{\circ} \mathrm{C}$ for 25 min before core insertion. The positive control cores were normal lung alveoli and squamous cell carcinoma of the lung for CD24 and SOX2, testicular seminoma for Oct4, benign urothelial epithelium of the bladder for CD44v6, normal umbilical cord for FGFR1, normal blood vessel for VEGF, and normal liver tissue for IGF-1.

\section{Immunohistochemistry}

The TMA blocks were cut into $4 \mu \mathrm{m}$ thick sections, mounted on silanized glass slides, and dried in an oven at $70^{\circ} \mathrm{C}$ for $60 \mathrm{~min}$. The slides were automatically processed and stained by BenchMark XT (Ventana, Roche Diagnostics, USA) according to the manufacturer's instructions. The procedure included antigen retrieval by heating at $70^{\circ} \mathrm{C}$ for $1 \mathrm{~h}$, followed by pretreatment with cell conditioner 2 ( $\mathrm{pH}$ 6) for $60 \mathrm{~min}$, and subsequent incubation with each antibody at optimal temperature for
$32 \mathrm{~min}$, and then counterstained by hematoxylin for 4 min and bluing agent for $4 \mathrm{~min}$, followed by chromogenic detection using UltraView Universal DAB Detection Kit for mins, and final washing step for mins. The stained slides were covered with balsamic acid. Immunohistochemical staining was performed for CK7, CK20, CDX-2, and MUC-2 and the tumors were classified into pancreaticobiliary and intestinal subtype. In addition, immunohistochemical staining was performed for stem cell markers including CD24, SOX2, Oct4, and CD44v6 and epithelial-mesenchymal transition markers, including VEGF, IGF-1, and FGFR1. The dilution and incubation conditions for each antibody are as follows: CK7 (Prediluted, Ventana, Roche Diagnostics, USA), CK20 (Prediluted, Ventana, Roche Diagnostics, USA), CDX-2 (Prediluted, Ventana, Roche Diagnostics, USA), MUC-2 (Prediluted, Ventana, Roche Diagnostics, USA), CD24 (1: 50, Thermo Scientific, UK), Oct4 (ChIP Grade ab19857, 1:100, Abcam, CB4, UK), SOX2 (SP76, 1:100, Cell Marque, CA, USA), VEGF (1:50, Quartett Immunodiagnostika, Berlin, Germany), IGF-1 (1:100, Abcam, CB4, UK), FGFR1 (ChIP Grade ab10646, 1:100, Abcam, CB4, UK) and CD44v6 (1:200, Invitrogen, CA, USA). The immunoreactivity was scored for each tissue microarray core as a three-tier system $(0,1+, 2+, 3+)$ according to the intensity. If the intensity is heterogeneously high or low, the most commonly found intensity was scored.

\section{Statistical analysis}

All analyses were performed using $\mathrm{R}$ statistical software (version 3.2.3 via http://web-r.org/) and IBM SPSS Statistics (ver. 1.0.0.1347 64-bit). Statistical analysis was performed using the Mann-Whitney test for continuous variables and Fisher's exact test or chi-square tests for categorical variables to compare the groups with and without recurrence For multivariable regression analysis, logistic regression analysis was used to evaluate the association between the clinicopathologic parameters and the recurrence.

Kaplan-Meier analysis was used for survival analysis to search the parameters affecting the overall survival and disease-free survival and results with a $p$-value less than 0.05 were considered as statistically significant. To find the novel panel of prognostic markers, the combined immunoreactivity score was made using the immunoreactivity of certain $2,3,4,5$ IHC markers and analyzed with overall survival. The group was divided into the lower and higher expression groups according to the expression level of the IHC panel. Using the statistically significant parameters in Kaplan-Meier analysis, Cox regression analysis was used to confirm the relationship and to determine the odds ratio of each parameter. 


\section{Results}

\section{Patient and tumor characteristics}

The clinicopathologic data of the evaluated cases are summarized in Table 1. Mean age of the patients was 63 years (ranging from 36 to 82). There were 76 male patient cases and 50 female patient cases $(\mathrm{M}: \mathrm{F}=1.52: 1)$. Originally, the epicenter of the tumor was diagnosed as periampullary duodenum in 3 cases, AOV in 37 cases, pancreatic head in 37 cases, distal CBD in 47 cases, and proximal CBD in 2 cases. After pathological revision, the epicenter of the tumor was AOV in 34 cases, pancreatic head in 44 cases, and distal CBD in 48 cases (Table 1 ). Changes in the original and revised diagnoses have been described in the following section and summarized in Table 2.

Grossly, 20 cases (15.9\%) were categorized as fungating type, $93(73.8 \%)$ as infiltrative, $3(2.4 \%)$ as ulcerofungating, $5(4.0 \%)$ as sessile, and $2(1.6 \%)$ as solid type. The mean tumor size was $3.2 \mathrm{~cm}$ (ranging from 0.6 to 8.0 $\mathrm{cm})$. Since tumor size $(>4.5 \mathrm{~cm})$ is one of the important prognostic markers for pancreatic cancer, the cases were divided into two groups based on tumor size $(<$ or $>$ than $4.5 \mathrm{~cm}$ ) and compared. There were 96 cases with smaller tumor size $(76.2 \%)$ and 30 cases with larger tumor size (23.8\%). Tumor classification based on N stage according to the AJCC staging system, showed that 73 cases (57.9\%) were N0, 53 were N1 (42.1\%), and there were no $\mathrm{N} 2$ cases. $M$ stage classification indicated that 8 cases (6.3\%) were M1, while the rest was M0 (117 cases, 93.7\%). Lymphatic invasion was found in 56 cases (44.4\%), vascular invasion in $16(12.7 \%)$, and perineural invasion in 72 cases $(57.1 \%)$. Positive radial resection margin was found in 8 cases $(6.3 \%)$. Tumor ulcer was found in 10 cases (7.9\%).

Classification according to histologic grade showed that originally, 37 cases $(29.4 \%)$ were diagnosed as welldifferentiated tumors, 79 (62.7\%) as moderately differentiated, and 10 as (7.9\%) poorly differentiated. After review, 32 (25.4\%) were well-differentiated, 90 (71.4\%) were moderately differentiated, and 4 (3.2\%) were poorly differentiated. In histologic subtypes, 34 cases (27.2\%) were pancreaticobiliary subtype, 58 (46.4\%) were more likely to be pancreaticobiliary subtype, 19 cases (15.2\%) were more likely to be intestinal subtype, and 14 cases (11.1\%) were of the intestinal subtype. Degree of accompanying fibrosis, known as desmoplastic reaction, was absent in 4 cases $(3.2 \%)$ in the original pathologic reports, mild in 20 cases (15.9\%), moderate in 72 cases (57.1\%), and severe in 30 cases $(23.8 \%)$. After revision, it was absent in 1 case $(0.8 \%)$, mild in 35 cases $(27.8 \%)$, moderate in 57 cases (45.2\%), and severe in 33 cases (26.2\%). Degree of peritumoral inflammation was mild in 53 cases $(42.1 \%)$ in the original pathologic reports, moderate in 62 cases (49.2\%) and severe in 11 cases
(8.7\%). After revision, it was mild in 42 cases (33.3\%), moderate in 70 cases (55.6\%), and severe in 14 cases (11.1\%). Tumor recurrence was observed in 61 cases (48.8\%) during an average follow-up of 969.7 days (ranged 3 to 5234 days). Disease-free survival duration was an average of 731.2 days (ranging from 3 to 4173 days). Eighty-seven out of 126 patients (69.0\%) were dead during the follow-up.

\section{Comparison of tumor epicenter and $\mathrm{T}$ stages between original and revised diagnoses}

Comparison of original and revised diagnoses showed that the epicenter of the tumor was altered in 22 out of 126 cases (17.4\%) (Table 2). Among the 22 cases, 10 cases showed a discrepancy between distal CBD and pancreatic head cancers, 6 cases showed a discrepancy between distal CBD and AOV cancers, 5 cases showed a discrepancy between pancreatic head and AOV cancers, 2 cases showed a discrepancy between periampullary duodenum and AOV, 2 cases showed a discrepancy between proximal and distal CBD, and 1 case showed a discrepancy between periampullary duodenum and distal CBD. As the tumor locations have been changed after the review, the $\mathrm{T}$ stages were also altered (Table 2). As a result, 6 cases showed different $T$ stage between the original and revised diagnoses with 3 overstaged and 3 understaged cases, respectively (6 out of 126 cases, $4.8 \%)$.

\section{Immunohistochemical staining and immunoreactivity results}

The immunohistochemical staining conditions are summarized in Table 3 and the representative images of the immunohistochemical stainings are shown in Supplementary Fig. 1. The immunoreactivity of SOX2 in the nucleus was negative in 13 cases (10.3\%), $1+$ in 66 cases (52.4\%), $2+$ in 45 cases (35.7\%) and $3+$ in 2 cases (1.6\%). The SOX2 immunoreactivity in the cytoplasm was negative in 66 cases $(52.4 \%), 1+$ in 56 cases (44.4\%), 2+ in 4 cases $(3.2 \%)$, and no cases showed $3+$. CD24 staining was negative in 6 cases (4.8\%), $1+$ in 79 cases $(62.7 \%)$, $2+$ in 37 cases $(29.4 \%)$, and $3+$ in 4 cases (3.2\%). Oct 4 immunoreactivity was $1+$ in 26 cases (20.6\%), $2+$ in 73 cases $(57.9 \%)$, and $3+$ in 27 cases $(21.4 \%)$. IGF-1 staining was negative in 13 cases (10.3\%), $1+$ in 74 cases $(58.7 \%)$, $2+$ in 33 cases $(26.2 \%)$, and $3+$ in 6 cases $(4.8 \%)$. The FGFR1 immunoreactivity was $1+$ in 7 cases $(5.6 \%), 2+$ in 52 cases $(41.3 \%)$, and $3+$ in 67 cases $(53.2 \%)$. The VEGF immunoreactivity was $1+$ in 18 cases (14.6\%), $2+$ in 78 cases $(63.4 \%)$, and $3+$ in 27 cases $(22.0 \%)$. CD44v6 staining was negative in 14 cases $(11.1 \%), 1+$ in 41 cases (32.5\%), $2+$ in 43 cases $(34.1 \%)$, and $3+$ in 28 cases $(22.2 \%)$. 
Table 1 Summary of clinicopathological data of the enrolled cases

\begin{tabular}{|c|c|c|c|c|}
\hline \multirow[b]{2}{*}{ Age (yrs) } & \multicolumn{4}{|c|}{ №. (\%) } \\
\hline & \multicolumn{2}{|c|}{ Ranged $36 \sim 82$} & \multicolumn{2}{|c|}{ Mean $63.0 \pm 9.4$} \\
\hline Sex & \multicolumn{2}{|c|}{ Male 76, Female 50} & \multicolumn{2}{|c|}{$M: F=1.52: 1$} \\
\hline Location (tumor epicenter) & \multicolumn{2}{|c|}{ Original diagnosis } & \multicolumn{2}{|c|}{ Revised diagnosis } \\
\hline Periampullary duodenum & 3 & $(2.4 \%)$ & 0 & $(0 \%)$ \\
\hline AOV & 37 & $(29.4 \%)$ & 34 & $(27.0 \%)$ \\
\hline Pancreatic head & 37 & (29.4\%) & 44 & $(34.9 \%)$ \\
\hline Distal CBD & 47 & (37.3\%) & 48 & (38.1\%) \\
\hline Proximal CBD & 2 & $(1.6 \%)$ & 0 & (0\%) \\
\hline T stage & \multicolumn{2}{|c|}{ Original diagnosis } & \multicolumn{2}{|c|}{ Revised diagnosis } \\
\hline Tis & 1 & $(0.8 \%)$ & 1 & $(0.8 \%)$ \\
\hline $\mathrm{T} 1$ & 21 & $(16.7 \%)$ & 21 & $(16.7 \%)$ \\
\hline $\mathrm{T} 2$ & 29 & (23.0\%) & 29 & $(23.0 \%)$ \\
\hline T3 & 67 & (53.2\%) & 67 & $(53.2 \%)$ \\
\hline T4 & 8 & $(6.3 \%)$ & 8 & $(6.3 \%)$ \\
\hline \multicolumn{5}{|l|}{ Gross type } \\
\hline Fungating & \multicolumn{2}{|l|}{20} & \multicolumn{2}{|l|}{ (15.9\%) } \\
\hline Infiltrative & \multicolumn{2}{|l|}{93} & \multicolumn{2}{|l|}{$(73.8 \%)$} \\
\hline Ulcerofungating & \multicolumn{2}{|l|}{3} & \multicolumn{2}{|l|}{$(2.4 \%)$} \\
\hline Sessile & \multicolumn{2}{|l|}{5} & \multicolumn{2}{|l|}{$(4.0 \%)$} \\
\hline Solid & \multicolumn{2}{|l|}{2} & \multicolumn{2}{|l|}{$(1.6 \%)$} \\
\hline Tumor size & \multicolumn{2}{|c|}{ Ranged $0.6 \sim 8.0 \mathrm{~cm}$} & \multicolumn{2}{|c|}{ Mean $3.2 \pm 1.6 \mathrm{~cm}$} \\
\hline$<4.5 \mathrm{~cm}$ & \multicolumn{2}{|l|}{96} & $(76.2 \%)$ & \\
\hline$\geq 4.5 \mathrm{~cm}$ & 30 & & $(23.8 \%)$ & \\
\hline N stage & & & & \\
\hline No & 73 & & $(57.9 \%)$ & \\
\hline $\mathrm{N} 1$ & 53 & & $(42.1 \%)$ & \\
\hline N2 & 0 & & $(0 \%)$ & \\
\hline M stage & & & & \\
\hline MO & 117 & & $(93.7 \%)$ & \\
\hline M1 & 8 & & $(6.3 \%)$ & \\
\hline & Abs & & Present & \\
\hline Lymphatic invasion & 70 & (55.6\%) & 56 & $(44.4 \%)$ \\
\hline Vascular invasion & 110 & (87.3\%) & 16 & $(12.7 \%)$ \\
\hline Perineural invasion & 54 & $(42.9 \%)$ & 72 & $(57.1 \%)$ \\
\hline Positive radial resected margin & 118 & (93.7\%) & 8 & $(6.3 \%)$ \\
\hline Tumor ulceration & 116 & (92.1\%) & 10 & $(7.9 \%)$ \\
\hline Histologic grade & & & & \\
\hline Well differentiated & 37 & (29.4\%) & 32 & $(25.4 \%)$ \\
\hline Moderately differentiated & 79 & $(62.7 \%)$ & 90 & $(71.4 \%)$ \\
\hline Poorly differentiated & 10 & $(7.9 \%)$ & 4 & $(3.2 \%)$ \\
\hline Histologic subtype & & & & \\
\hline Pancreaticobiliary subtype & 34 & & $(27.2 \%)$ & \\
\hline Prone to pancreaticobiliary subtype & 58 & & $(46.4 \%)$ & \\
\hline Prone to intestinal subtype & 19 & & $(15.2 \%)$ & \\
\hline
\end{tabular}


Table 1 Summary of clinicopathological data of the enrolled cases (Continued)

\begin{tabular}{|c|c|c|c|c|}
\hline \multirow[b]{2}{*}{ Age (yrs) } & \multicolumn{4}{|c|}{ No. (\%) } \\
\hline & \multicolumn{2}{|c|}{ Ranged $36 \sim 82$} & \multicolumn{2}{|c|}{ Mean $63.0 \pm 9.4$} \\
\hline Intestinal subtype & \multicolumn{2}{|l|}{14} & \multicolumn{2}{|c|}{$(11.2 \%)$} \\
\hline Degree of fibrosis & \multicolumn{2}{|c|}{ Original diagnosis } & \multicolumn{2}{|c|}{ Revised diagnosis } \\
\hline Absent & 4 & $(3.2 \%)$ & 1 & $(0.8 \%)$ \\
\hline Mild & 20 & $(15.9 \%)$ & 35 & $(27.8 \%$ \\
\hline Moderate & 72 & $(57.1 \%)$ & 57 & $(45.2 \%$ \\
\hline Severe & 30 & $(23.8 \%)$ & 33 & $(26.2 \%$ \\
\hline Degree of inflammation & \multicolumn{2}{|c|}{ Original diagnosis } & \multicolumn{2}{|c|}{ Revised diagnosis } \\
\hline Mild & 53 & $(42.1 \%)$ & 42 & $(33.3 \%$ \\
\hline Moderate & 62 & $(49.2 \%)$ & 70 & $(55.6 \%$ \\
\hline Severe & 11 & $(8.7 \%)$ & 14 & $(11.1 \%$ \\
\hline \multirow[t]{2}{*}{ Tumor recurrence } & Abse & & Pres & \\
\hline & 64 & $(51.2 \%)$ & 61 & $(48.8 \%$ \\
\hline Death & 39 & $(31.0 \%)$ & 87 & $(69.0 \%$ \\
\hline Follow-up duration (days) & \multicolumn{2}{|c|}{ Ranged $3 \sim 5234$} & \multicolumn{2}{|c|}{$969.7 \pm 1135$} \\
\hline Disease free survival (days) & \multicolumn{2}{|c|}{ Ranged $3 \sim 4173$} & \multicolumn{2}{|c|}{$731.2 \pm 954.5$} \\
\hline
\end{tabular}

\section{Clinicopathological parameters related to tumor recurrence}

There was no significant difference between the recurrence and non-recurrence groups based on age, gender, original, revised and combined locations, gross type, ulcer, tumor size, presence or absence of radial resection margin, $\mathrm{N}$ stage, and $\mathrm{M}$ stage. Although there were no statistically significant relationships between $\mathrm{T}$ stage and recurrence, there was a tendency that the recurrence group had a higher $\mathrm{T}$ stage than the non-recurrence group. Moreover, there was no statistically significant difference observed between the pathological parameters such as lymphatic invasion, vascular invasion, perineural invasion, histological deferentiation, degree of fibrosis, degree of inflammation, histological subtype and the markers detected by IHC (CK7, CK20, CDX-2, MUC-2,

Table 2 Comparison of tumor epicenter and T stages between original and revised diagnoses

\begin{tabular}{|c|c|c|c|c|c|c|}
\hline \multicolumn{7}{|l|}{ (A) } \\
\hline & \multicolumn{6}{|c|}{ Revised tumor epicenter } \\
\hline Original tumor epicenter & Periampullary duodenum & AOV & Pancreatic head & Distal CBD & Proximal CBD & Total \\
\hline Periampullary duodenum & 0 & 2 & 0 & 1 & 0 & 3 \\
\hline AOV & 0 & 29 & 3 & 5 & 0 & 37 \\
\hline Pancreatic head & 0 & 2 & 33 & 2 & 0 & 37 \\
\hline Distal CBD & 0 & 1 & 8 & 38 & 0 & 47 \\
\hline Proximal CBD & 0 & 0 & 0 & 2 & 0 & 2 \\
\hline Total & 0 & 34 & 44 & 48 & 0 & 126 \\
\hline \multicolumn{7}{|l|}{ (B) } \\
\hline & \multicolumn{6}{|c|}{ Revised T stage } \\
\hline Original T stage & Tis & $\mathrm{T} 1$ & $\mathrm{~T} 2$ & $\mathrm{~T} 3$ & T4 & Total \\
\hline Tis & 1 & 0 & 0 & 0 & 0 & 1 \\
\hline $\mathrm{T} 1$ & 0 & 21 & 0 & 0 & 0 & 21 \\
\hline $\mathrm{T} 2$ & 0 & 0 & 27 & 2 & 0 & 29 \\
\hline T3 & 0 & 0 & 2 & 64 & 1 & 67 \\
\hline T4 & 0 & 0 & 0 & 1 & 7 & 8 \\
\hline Total & 1 & 21 & 29 & 67 & 8 & 126 \\
\hline
\end{tabular}


Table 3 Condition of immunohistochemical stains and the immunoreactivity

\begin{tabular}{|c|c|c|c|c|c|c|c|c|c|c|c|c|c|c|c|c|}
\hline \multirow{2}{*}{$\frac{\text { IHC markers }}{\text { Vendor }}$} & \multicolumn{2}{|c|}{$\mathrm{SOX} 2(\mathrm{Nu})$} & \multicolumn{2}{|c|}{ SOX2 (Cyto) } & \multicolumn{2}{|c|}{$\mathrm{CD} 24$} & \multicolumn{2}{|c|}{ Oct4 } & \multicolumn{2}{|c|}{ IGF-1 } & \multicolumn{2}{|c|}{ FGFR } & \multicolumn{2}{|c|}{ VEGF } & \multicolumn{2}{|c|}{ CD44v6 } \\
\hline & \multicolumn{4}{|c|}{ Cell Marque (SP76) } & \multicolumn{2}{|c|}{$\begin{array}{l}\text { Thermo } \\
\text { Scientific }\end{array}$} & \multicolumn{2}{|c|}{ abcam } & \multicolumn{2}{|c|}{ abcam } & \multicolumn{2}{|c|}{ abcam } & \multicolumn{2}{|c|}{$\begin{array}{l}\text { Quartett } \\
\text { Immunodiagnostika }\end{array}$} & \multicolumn{2}{|c|}{ Invitrogen } \\
\hline Dilution & $1: 10$ & & & & $1: 50$ & & $1: 100$ & & $1: 10$ & & $1: 100$ & & $1: 50$ & & $1: 200$ & \\
\hline \multirow[t]{2}{*}{ Positive control } & \multicolumn{6}{|c|}{$\begin{array}{l}\text { Normal lung alveoli and squamous } \\
\text { cell carcinoma }\end{array}$} & \multicolumn{2}{|c|}{$\begin{array}{l}\text { Testicular } \\
\text { seminoma }\end{array}$} & \multicolumn{2}{|c|}{$\begin{array}{l}\text { Normal } \\
\text { liver }\end{array}$} & \multicolumn{2}{|c|}{$\begin{array}{l}\text { Normal } \\
\text { umbilical cord }\end{array}$} & \multicolumn{2}{|c|}{ Blood vessel } & \multicolumn{2}{|c|}{$\begin{array}{l}\text { Benign urothelia } \\
\text { epithelium }\end{array}$} \\
\hline & No. & $(\%)$ & No. & $(\%)$ & No. & $(\%)$ & No. & (\%) & No. & $(\%)$ & No. & $(\%)$ & No. & $(\%)$ & No. & $(\%)$ \\
\hline 0 & 13 & (10.3) & 66 & $(52.4)$ & 6 & $(4.8)$ & 0 & $(0.0)$ & 13 & $(10.3)$ & 0 & $(0.0)$ & 0 & $(0.0)$ & 14 & $(11.1)$ \\
\hline $1+$ & 66 & $(52.4)$ & 56 & $(44.4)$ & 79 & (62.7) & 26 & (20.6) & 74 & $(58.7)$ & 7 & (5.6) & 18 & $(14.6)$ & 41 & $(32.5)$ \\
\hline $2+$ & 45 & (35.7) & 4 & (3.2) & 37 & (29.4) & 73 & $(57.9)$ & 33 & $(26.2)$ & 52 & $(41.3)$ & 78 & $(63.4)$ & 43 & $(34.1)$ \\
\hline $3+$ & 2 & (1.6) & 0 & $(0.0)$ & 4 & (3.2) & 27 & (21.4) & 6 & $(4.8)$ & 67 & (53.2) & 27 & $(22.0)$ & 28 & $(22.2)$ \\
\hline Total & 126 & (100) & 126 & (100) & 126 & (100) & 126 & (100) & 126 & (100) & 126 & (100) & 123 & (100) & 126 & (100) \\
\hline
\end{tabular}

SOX2 (nuclear), SOX2 (cytoplasmic), CD24, Oct4, IGF1, FGFR1, VEGF, and CD44v6). However, the only significant difference was observed in the original degree of fibrosis $(p=0.020)$ as indicated in Table 4. However, the multivariable regression analysis showed no statistical differences among all clinicopathological parameters according to tumor recurrence (data not shown).

\section{Disease-free survival analysis in recurrence patient}

The clinical parameters such as age $<74(p=0.0221)$, location of $\operatorname{AOV}(p=0.014)$, lower T stage $(\mathrm{p}=0.02)$, size less than $1.5 \mathrm{~cm}(p=0.0426)$, lower $\mathrm{N}$ stage (N0) $(p=$ 0.000391 ) were significantly associated with better disease-free survival (DFS) in recurrent patients, whereas, no significant correlation was observed in other parameters (Supplementary Fig. 2).

In addition, other pathological parameters including no lymphatic invasion $(p<0.0001)$, histological well differentiation $(p=0.00121)$, intestinal subtype $(p=$ $0.0417)$, and mild fibrosis $(p=0.0259)$ showed a significant association with better DFS (Supplementary Fig. 3). In addition, IHC markers such as CDX-2 $(p=0.0245)$ and FGFR1 $(p=0.0181)$ were also significantly correlated with better DFS (Supplementary Fig. 4). Cox regression analysis showed no significant relation of any clinicopathologic parameters to DFS (data not shown).

\section{Clinicopathological parameters related to overall survival}

Among clinical parameters, age $(p=0.0527)$ and gender $(p=0.908)$ were not associated with overall survival. On the other hand, location of AOV $(p<0.0001)$, lower T stage $(p=0.000228)$, sessile and solid gross type $(p=$ $0.00278)$, size less than $1.5 \mathrm{~cm}(p=0.00727)$, lower $\mathrm{N}$ stage $(\mathrm{N} 0)(\mathrm{p}<0.0001)$, and lower $\mathrm{M}$ stage $(\mathrm{M} 0)(p=$ $0.000139)$ were significantly related to better overall survival (Fig. 1). Among pathological parameters, better overall survival was related to no lymphatic invasion $(P<0.0001)$, no vascular invasion $(p=0.000325)$, no perineural invasion $(p=0.00145)$, histological well differentiation $(p=0.000793)$, intestinal subtype $(p=$ $0.000483)$, no fibrosis $(p=0.00497)$, and severe inflammation ( $p=0.036)$ (Fig. 2). In addition, expression of four IHC markers, higher expression of intestinal-type markers, CK20 $(p=0.0135)$ and CDX2 $(p=0.000135)$, and higher expression of EMT markers, FGFR1 ( $\mathrm{p}=$ $0.0014)$ and VEGF $(p=0.0333)$ were significantly related to better overall survival (Fig. 3). The combined panel expression score more than 8 of CK20, CDX2, FGFR1, VEGF, and IGF-1 was significantly related to better overall survival $(p=0.000445)$ as well as the combined panel expression score more than 6 of CK20, CDX2, FGFR1, and VEGF $(p<0.0001)$ (Fig. 3). Cox regression analysis also showed a significant relationship of $\mathrm{N}$ stage, lymphatic invasion, degree of inflammation, pancreaticobiliary/ intestinal subtypes, expression of intestinal markers, CK20 and CDX2, and EMT markers, FGFR1 and VEGF (Supplementary Table 2, Supplementary Fig. 5).

\section{Discussion}

The two major findings in this study are, first, FGFR1 could be a promising prognostic marker for periampullary cancers, and second, peritumoral fibrosis was associated with tumor recurrence in periampullary cancer patients. We also confirmed significant relationship between overall survival and previously known clinicopathological prognostic markers, such as age, location, $\mathrm{T}$ stage, gross type, size, $\mathrm{N}$ stage, $\mathrm{M}$ stage, lymphatic invasion, vascular invasion, perineural invasion, histological differentiation, inflammation and the staining pattern of the IHC markers (CK20, CDX2), as described in the literature $[1,12]$.

In the present study, FGFR1 is significantly associated with overall survival and disease-free survival in periampullary/pancreatic cancer patients. FGFR1 has been known to be related to the prognosis of several human cancers $[9,13]$. It is a member of the tyrosine kinase family and shares similar structural morphology with VEGFRs and platelet-derived growth factor receptors 
Table 4 Clinicopathological parameters related to tumor recurrence

\begin{tabular}{llll}
\hline $\begin{array}{l}\text { Clinicopathologic } \\
\text { parameters }\end{array}$ & No. (\%) & P value \\
\cline { 2 - 3 } & $\begin{array}{l}\text { Non-recurrence } \\
(N=58)\end{array}$ & $\begin{array}{l}\text { Recurrence } \\
(N=61)\end{array}$ & \\
\hline Age (yrs) & $62.4 \pm 9.9$ & $64.4 \pm 8.9$ & 0.258
\end{tabular}

Sex

$\begin{array}{llll}\text { Male } & 37(63.8 \%) & 36(59.0 \%) & 0.729 \\ \text { Female } & 21(36.2 \%) & 25(41.0 \%) & \\ \text { Original location (epicenter) } & & & 0.347\end{array}$

Original location (epicenter)

Periampullary duodenum

AOV

$2(3.4 \%)$

$1(1.6 \%)$

Pancreatic head

$20(34.5 \%)$

$16(26.2 \%)$

Distal CBD

Proximal CBD

$15(25.9 \%)$

$16(26.2 \%)$

$19(32.8 \%)$

$28(45.9 \%)$

Revised location (epicenter)

AOV

\section{$0(0.0 \%)$}

$0(0.0 \%)$

Combined location (epicenter)

\section{AOV \\ Pancreatic head}

Distal CBD

Original T stage

Tis
T1
T2
T3
T4

Gross type

$\begin{array}{lll}\text { Fungating } & 12(21.4 \%) & 8(13.3 \%) \\ \text { Infiltrative } & 37(66.1 \%) & 50(83.3 \%) \\ \text { Ulcerofungating } & 2(3.6 \%) & 1(1.7 \%) \\ \text { Sessile } & 3(5.4 \%) & 1(1.7 \%) \\ \text { Solid } & 2(3.6 \%) & 0(0.0 \%)\end{array}$

Ulcer

Absent

\section{Average tumor size}

Tumor size $<4.5 \mathrm{~cm}$

$$
\geq 4.5 \mathrm{~cm}
$$

$54(93.1 \%)$

$4(6.9 \%)$

$3.0 \pm 1.5$

$47(81.0 \%)$

$11(19.0 \%)$

$56(96.6 \%)$

Absent

$$
\begin{aligned}
& \text { Present } \\
& \text { No. of positive lymph nodes }
\end{aligned}
$$$$
2(3.4 \%)
$$

No. of dissected lymph nodes

NA

0.536

$35(57.4 \%)$

$3(4.9 \%)$

NA

$3.3 \pm 1.7$

0.199

$44(72.1 \%)$

0.353

$17(27.9 \%)$

$57(93.4 \%)$

0.722

$4(6.6 \%)$

$1.2 \pm 1.8 \quad 0.073$

$11.2 \pm 7.0$

0.730

$11.6+7.4$
Table 4 Clinicopathological parameters related to tumor recurrence (Continued)

\begin{tabular}{llll}
\hline $\begin{array}{l}\text { Clinicopathologic } \\
\text { parameters }\end{array}$ & $\begin{array}{l}\text { No. }(\%) \\
\text { Non-recurrence } \\
(N=58)\end{array}$ & $\begin{array}{l}\text { Recurrence } \\
(N=61)\end{array}$ & \\
\hline N stage & & & \\
N0 & $38(65.5 \%)$ & $34(55.7 \%)$ & 0.366 \\
N1 & $20(34.5 \%)$ & $27(44.3 \%)$ &
\end{tabular}

M stage

$\begin{array}{llll}\text { M0 } & 55(94.8 \%) & 60(98.4 \%) & 0.575 \\ \text { M1 } & 3(5.2 \%) & 1(1.6 \%) & \\ \text { Lymphatic invasion Absent } & 38(65.5 \%) & 30(49.2 \%) & 0.106 \\ \text { Present } & 20(34.5 \%) & 31(50.8 \%) & \\ \text { Vascular invasion } & & & \\ \text { Absent } & 51(87.9 \%) & 53(86.9 \%) & 1.000 \\ \text { Present } & 7(12.1 \%) & 8(13.1 \%) & \\ \text { Perineural invasion Absent } & 27(46.6 \%) & 26(42.6 \%) & 0.805 \\ \text { Present } & 31(53.4 \%) & 35(57.4 \%) & \\ \text { Histologic grade } & & & 0.845\end{array}$

Well differentiated

$17(29.3 \%)$

17 (27.9\%)

Moderately differentiated

$37(63.8 \%)$

$38(62.3 \%)$

Poorly differentiated

$4(6.9 \%)$

$6(9.8 \%)$

Degree of fibrosis

$0.020^{*}$

None
Mild
Moderate
Severe

$4(6.9 \%)$

$0(0.0 \%)$

$9(14.8 \%)$

$33(54.1 \%)$

$19(31.1 \%)$

Degree of inflammation

$36(62.1 \%)$

$7(12.1 \%)$

0.415

Mild

$21(36.2 \%)$

$28(45.9 \%)$

Moderate

$30(51.7 \%)$

$29(47.5 \%)$

Severe

$7(12.1 \%)$

$4(6.6 \%)$

Histologic subtype

Pancreaticobiliary subtype 8 (14.0\%)

$21(34.4 \%)$

Prone to $29(50.9 \%)$

$28(45.9 \%)$

pancreaticobiliary subtype

Prone to intestinal

$10(17.5 \%)$

$8(13.1 \%)$ subtype

$10(17.5 \%)$

$4(6.6 \%)$

Intestinal subtype

$8(13.8 \%)$

$2(3.3 \%)$

0.145

CK7

Negative
$1+$
$2+$
$3+$
CK2O

$5(8.6 \%)$

$5(8.2 \%)$

$10(17.2 \%)$

$17(27.9 \%)$

Negative

35 (60.3\%)

$37(60.7 \%)$

$1+$

$2+$

28 (48.3\%)

42 (68.9\%)

0.110 
Table 4 Clinicopathological parameters related to tumor recurrence (Continued)

\begin{tabular}{|c|c|c|c|}
\hline \multirow{2}{*}{$\begin{array}{l}\text { Clinicopathologic } \\
\text { parameters }\end{array}$} & \multicolumn{2}{|l|}{ No. (\%) } & \multirow[t]{2}{*}{$P$ value } \\
\hline & $\begin{array}{l}\text { Non-recurrence } \\
(N=58)\end{array}$ & $\begin{array}{l}\text { Recurrence } \\
(N=61)\end{array}$ & \\
\hline \multicolumn{4}{|l|}{$\operatorname{CDX}$} \\
\hline Negative & $13(22.4 \%)$ & $21(34.4 \%)$ & \multirow[t]{4}{*}{0.086} \\
\hline $1+$ & $18(31.0 \%)$ & $23(37.7 \%)$ & \\
\hline $2+$ & $10(17.2 \%)$ & $10(16.4 \%)$ & \\
\hline $3+$ & $17(29.3 \%)$ & $7(11.5 \%)$ & \\
\hline \multicolumn{4}{|l|}{ MUC } \\
\hline Negative & $51(87.9 \%)$ & $56(91.8 \%)$ & \multirow[t]{2}{*}{0.692} \\
\hline Positive & 7 (12.1\%) & $5(8.2 \%)$ & \\
\hline SOX2 (nuclear) Negative & $5(8.6 \%)$ & $6(9.8 \%)$ & \multirow[t]{4}{*}{0.497} \\
\hline $1+$ & $31(53.4 \%)$ & $31(50.8 \%)$ & \\
\hline $2+$ & $20(34.5 \%)$ & $24(39.3 \%)$ & \\
\hline $3+$ & $2(3.4 \%)$ & $0(0.0 \%)$ & \\
\hline $\begin{array}{l}\text { SOX2 (cytoplasmic) } \\
\text { Negative }\end{array}$ & $30(51.7 \%)$ & $32(52.5 \%)$ & \multirow[t]{3}{*}{0.107} \\
\hline $1+$ & $24(41.4 \%)$ & $29(47.5 \%)$ & \\
\hline $2+$ & $4(6.9 \%)$ & $0(0.0 \%)$ & \\
\hline \multicolumn{4}{|l|}{ CD24 } \\
\hline Negative & $4(6.9 \%)$ & $2(3.3 \%)$ & \multirow[t]{4}{*}{0.728} \\
\hline $1+$ & $37(63.8 \%)$ & $37(60.7 \%)$ & \\
\hline $2+$ & $15(25.9 \%)$ & $20(32.8 \%)$ & \\
\hline $3+$ & $2(3.4 \%)$ & $2(3.3 \%)$ & \\
\hline \multicolumn{4}{|l|}{ OCT4 } \\
\hline $1+$ & $12(20.7 \%)$ & $14(23.0 \%)$ & \multirow[t]{3}{*}{0.943} \\
\hline $2+$ & $34(58.6 \%)$ & $34(55.7 \%)$ & \\
\hline $3+$ & $12(20.7 \%)$ & $13(21.3 \%)$ & \\
\hline \multicolumn{4}{|l|}{ |GF-1 } \\
\hline Negative & $7(12.1 \%)$ & $6(9.8 \%)$ & \multirow[t]{4}{*}{0.778} \\
\hline $1+$ & $32(55.2 \%)$ & $38(62.3 \%)$ & \\
\hline $2+$ & $16(27.6 \%)$ & $14(23.0 \%)$ & \\
\hline $3+$ & $3(5.2 \%)$ & $3(4.9 \%)$ & \\
\hline \multicolumn{4}{|l|}{ FGFR } \\
\hline $1+$ & $3(5.2 \%)$ & $4(6.6 \%)$ & \multirow[t]{3}{*}{0.697} \\
\hline $2+$ & 22 (37.9\%) & 27 (44.3\%) & \\
\hline $3+$ & 33 (56.9\%) & 30 (49.2\%) & \\
\hline \multicolumn{4}{|l|}{ VEGF } \\
\hline $1+$ & $6(10.3 \%)$ & $10(17.2 \%)$ & \multirow[t]{3}{*}{0.547} \\
\hline $2+$ & 38 (65.5\%) & $36(62.1 \%)$ & \\
\hline $3+$ & $14(24.1 \%)$ & $12(20.7 \%)$ & \\
\hline CD44v6 Negative & $6(10.3 \%)$ & $6(9.8 \%)$ & \multirow[t]{4}{*}{0.927} \\
\hline $1+$ & $18(31.0 \%)$ & $22(36.1 \%)$ & \\
\hline $2+$ & 21 (36.2\%) & 19 (31.1\%) & \\
\hline $3+$ & $13(22.4 \%)$ & $14(23.0 \%)$ & \\
\hline
\end{tabular}

(PDGFRs), which implies the potential role of FGFR1 in the carcinogenesis of many human cancers [9, 13]. Many reports including data from the cancer genome atlas study have provided evidence regarding the involvement of FGFRs in the carcinogenesis of several cancers such as primary lobular breast carcinomas (20\%) [14], lung cancer (22\%) [15], and pancreatic cancer (5\%) [16]. However, the prognostic impact of FGFR1 expression in cancer shows conflicting results depending on cancer types. Higher expression of the FGFR1 gene predicts poor overall survival and shorter disease-free survival in esophageal squamous cell carcinoma [17] and similar results were observed in non-small-cell lung cancer, particularly squamous cell carcinoma [18].

On the other hand, a recent study performed in the Korean patients showed that FGFR1 positive pancreatic cancer had better overall survival as compared to FGFR1 negative pancreatic cancer [19], which is consistent with the findings of our study. Although the precise reason for this discrepancy in different cancer types is unclear, it could probably be due to the different pathogenic roles of FGFR1 in various cancers. High expression of FGFR1 might cause a severe desmoplastic reaction (increased fibrosis) and could be protective or antitumorigenic in pancreatic cancers.

On the other hand, in this study, we found that the degree of peritumoral fibrosis was related to tumor recurrence. Although this finding seems conflicting with the first finding, high FGFR1 expression is correlated with the degree of fibrosis but is not strictly linked together. In pancreatic cancer, pancreatic stellate cells (PSCs) in the stroma are considered as the sprouting seeds of cancer progression and metastasis [20]. These are essential components of the tumor-stromal organization and are usually present as quiescent or inactive cells in normal pancreatic tissue. These cells are believed to play a key role in extracellular matrix production and regulate or promote EMT [2, 20]. It is possible that after surgery, tumors with a higher degree of fibrosis might have increased remnant fibrotic tissue containing activated PSCs, and this could be the foci of recurrence. In a recent study in colorectal cancers, fibrosis in metastatic lymph nodes was strongly associated with poor overall survival and relapse-free survival [21], suggesting that the fibrosis in the metastatic lymph nodes can be a potential foci of tumor recurrence. In our study, recurrence was also related to lymph node metastasis.

EMT is very important for the progression and metastasis of many cancers. It is particularly crucial in pancreatic cancer because histologically, pancreatic cancer is characterized by increased mesenchymal as well as epithelial features compared to other adenocarcinomas in other organs. In EMT, the epithelial cells lose polarity and cell to cell contact, have decreased E-cadherin 
A.

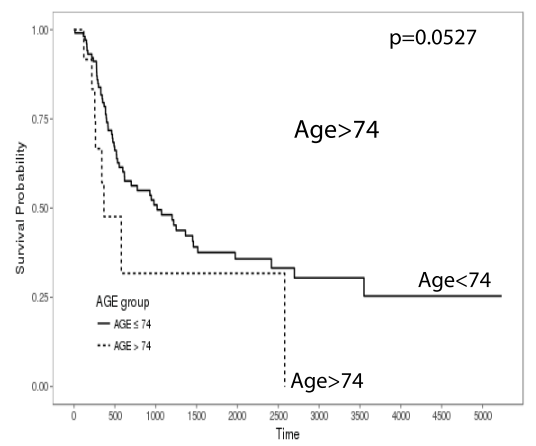

C.
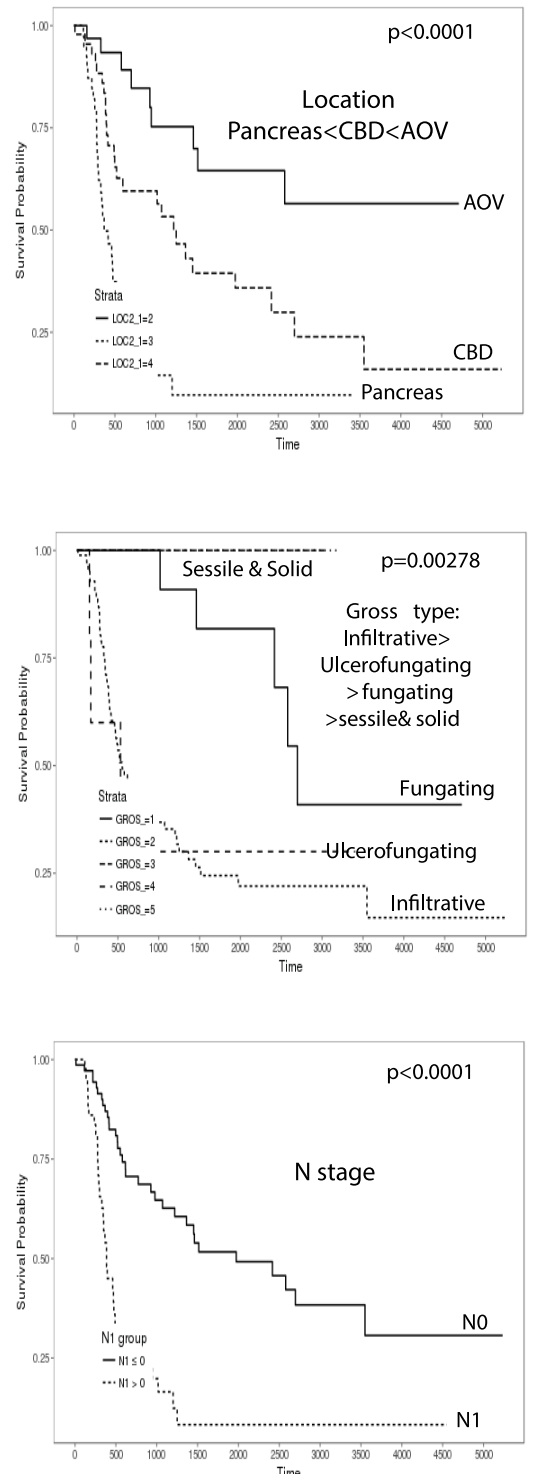
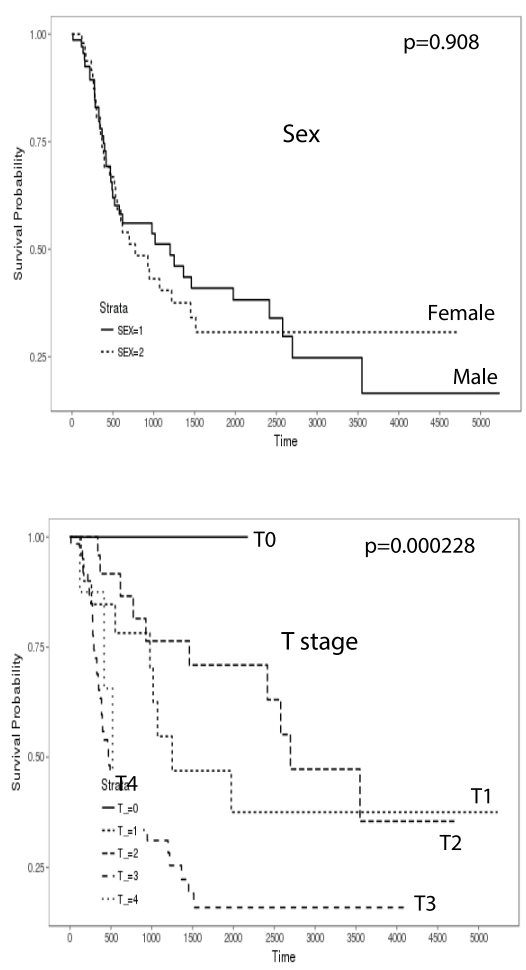

F.
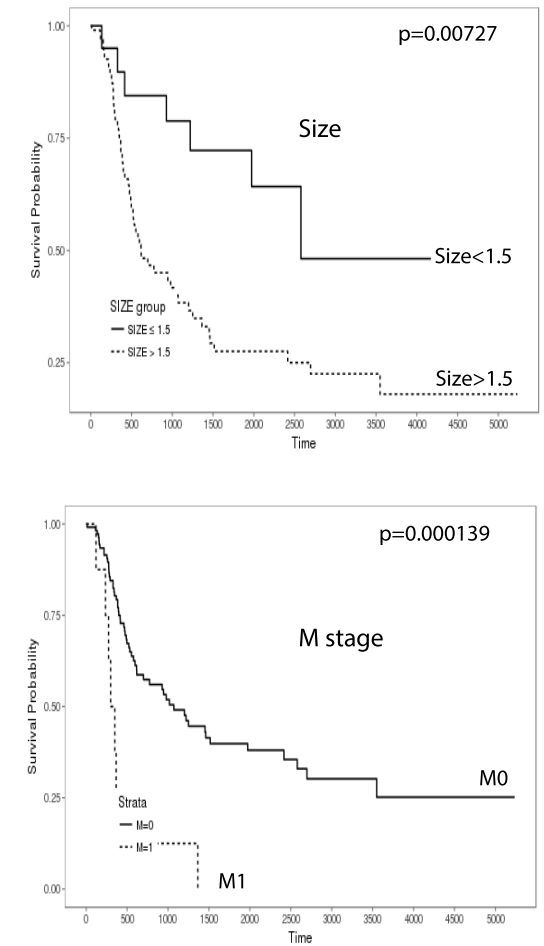

Fig. 1 Kaplan-Meier survival analysis on the relationship between overall survival and clinical parameters in periampullary/pancreatic cancers. There was no significant difference according to (a) age and (b) sex, while there was significant relationship according to (c) location, (d) T stage, (e) gross type, (f) size, (g) N stage, and (h) M stage 
A.

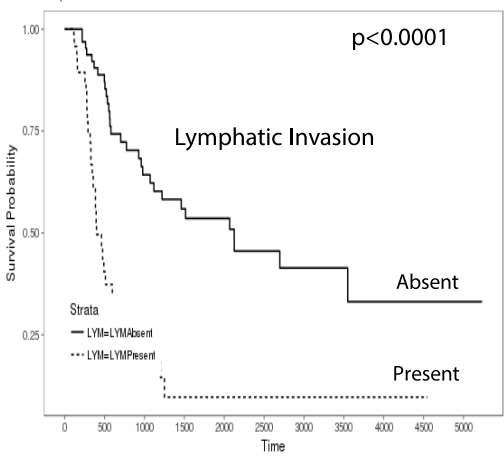

C.

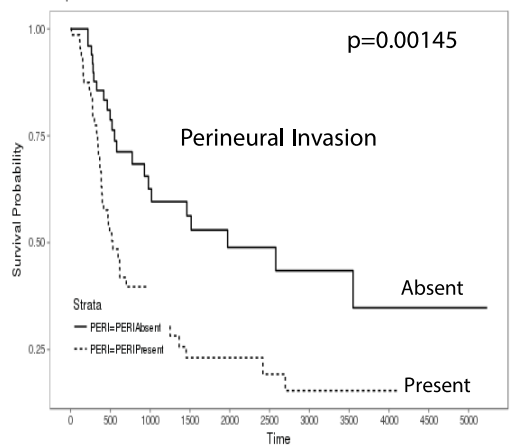

E.

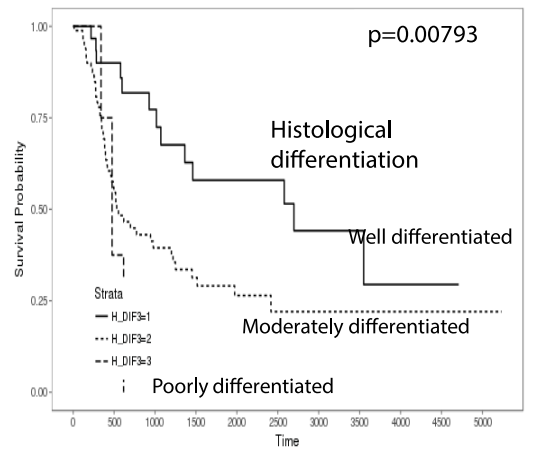

G.

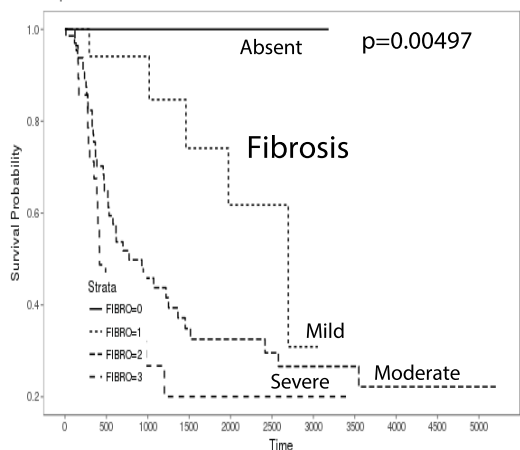

B.

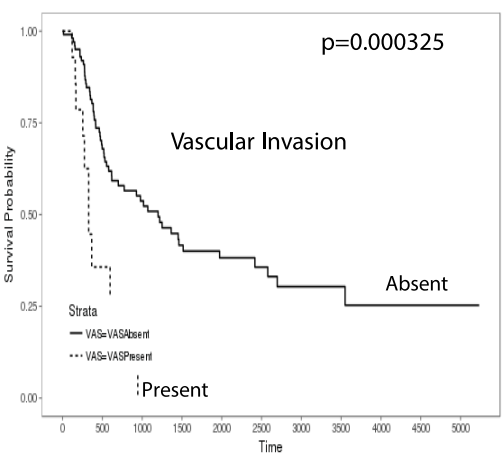

D.

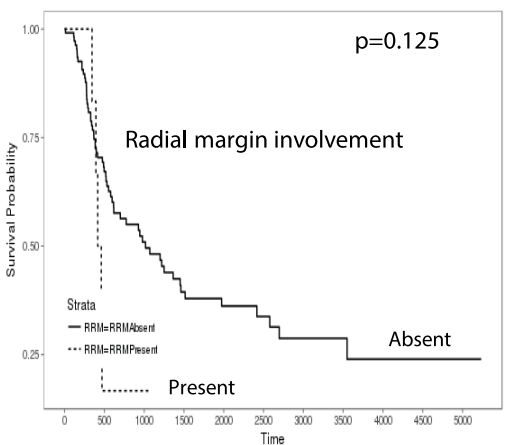

F.

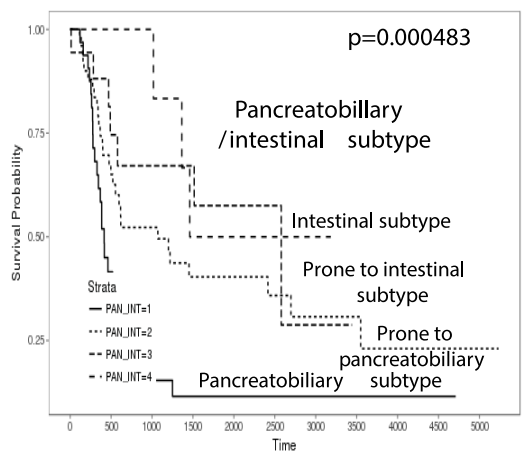

$\mathrm{H}$.

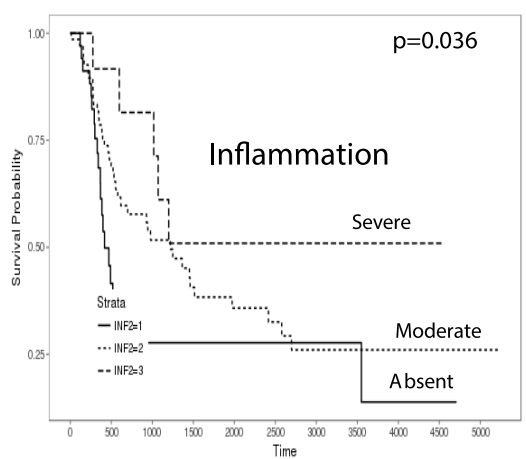

Fig. 2 Kaplan-Meier survival analysis on the relationship between overall survival and the pathological parameters in the periampullary/pancreatic cancers. There was significant difference according to a lymphatic invasion, b vascular Invasion, c perineural invasion, e histological differentiation, $\mathbf{f}$ pancreatobillary/intestinal type, $\mathbf{g}$ fibrosis, and $\mathbf{h}$ inflammation, whereas there was no significant difference according to $\mathbf{d}$ radial margin involvement 
A.

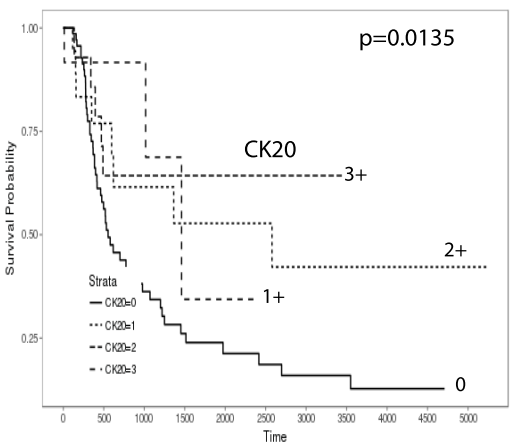

C.
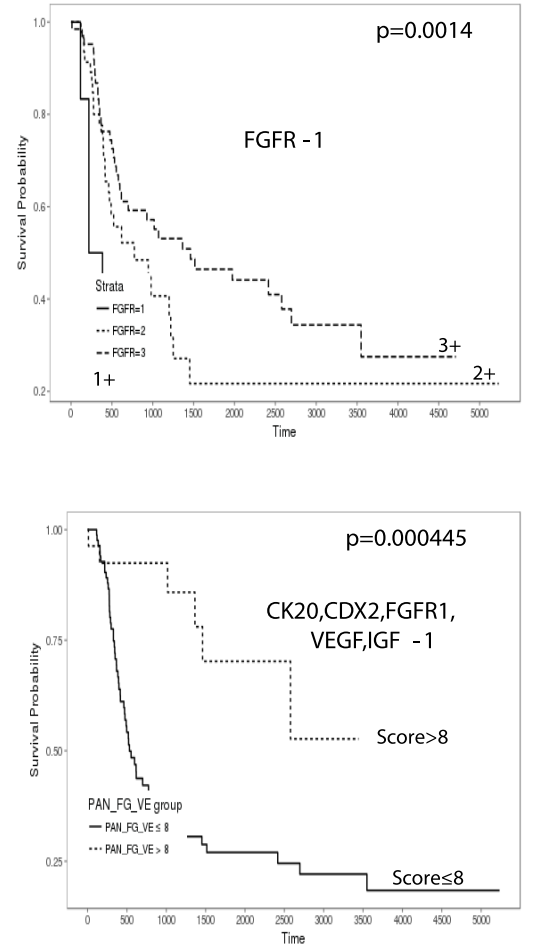

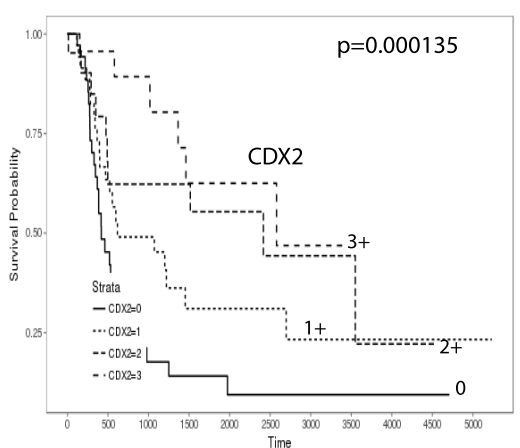

D.

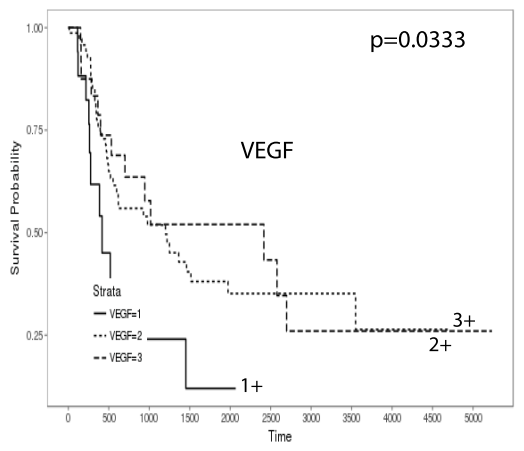

F.

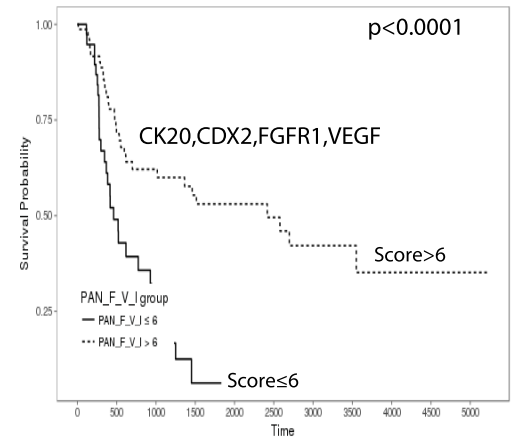

Fig. 3 Kaplan-Meier overall survival analysis on the relationship between overall survival and expression level of the IHC markers in periampullary/ pancreatic cancers. There was significant difference according to a CK20, b CDX2, c FGFR1, d VEGF, e combined CK20, CDX2, FGFR1, VEGF, and IGF-1 (combined score of 5 marker expression levels, 2ᄀ15), and $\mathbf{f}$ combined CK20,CDX2, FGFR1, and VEGF (combined score of 4 marker expression levels, 2ᄀ12)

expression and increased vimentin expression during the mesenchymal transition [8]. However, the loss of Ecadherin is usually exclusively found in metastatic lesions and the vimentin is well known for non-specific, frequent coexpression in pancreatic cancers. Therefore, the feasibility as a prognostic marker seems to be limited although a few studies have suggested these as potential prognostic markers [22].

On the other hand, the EMT marker VEGF shares similar structural morphology with FGFRs, and both are very important for angiogenesis [9]. It has been reported that the expression of VEGF and FGFR1 were correlated with microvessels density [13]. Generally, VEGF is associated with poor overall survival in cancer. Yousuke et al. demonstrated that high VEGF expression showed significantly worse survival compared to low VEGF expression in pancreatic adenocarcinoma [23]. Surprisingly, in our study, we found a positive relationship between VEGF expression and overall survival, which is opposed to that of previous studies. In addition, the combined panel expression of CK20, CDX2, FGFR1, VEGF, and IGF-1 and CK20, CDX2, FGFR1, and VEGF were also useful prognostic markers for better survival. 
In terms of stem cell markers, no stems cell markers including Oct4, SOX2, CD24, and CD44v6, showed significant relationship either with overall survival and disease-free survival. Higher expression of SOX2 and Oct4 has been reported to be associated with worse survival in some cancers, such as esophageal carcinoma [24]. As mentioned in the introduction, the aberrant expression of stem cell markers, such as Oct4, SOX2, CD24, CD44, PDX-1, SHH, and CD133, was suggested to be related to the prognosis in pancreatic cell lines, according to several studies $[7,25]$. However, there are no studies so far conducted on the human hosts but only in the cell lines about the aforementioned markers. Our study investigated the clinical and prognostic significance of the stem cell marker expression in a large number of pancreatic cancer samples, and the result was not significant among all markers, which was opposed to the results of the studies using the cell lines. One thing to notice, Quint et al. have reported that the expression of stem cell markers, Ptc and PDX-1, is related to survival in certain grades of pancreatic cancers using 51 cases [26].

In this study, we reevaluated the $\mathrm{T}$ stage according to the tumor epicenter and, 22 out of 126 cases $(17.4 \%)$ have been revised. Although it is not as high as reported by Adsay et al. (39\%) [2], the number of cases with the revised $\mathrm{T}$ stage was considerably high and therefore, cannot be neglected. Due to the anatomic complexity, determining the tumor epicenter correctly when the tumor is detected in the advanced stage is a complicated issue. In this study, although we evaluated the difference in $\mathrm{T}$ staging based on the 7th AJCC cancer staging system, the results would be similar in the 8th edition as well. The determination of tumor epicenter is the most important factor to differentiate AOV, pancreatic, and CBD cancers and the $\mathrm{T}$ stage of 8th edition AJCC system is also based on the different size standards according to the location [27]. In our suggestion, pancreaticobiliary/intestinal subtypes, according to the expression status of CK20 and CDX2, can be a good supportive parameter for better TNM staging. The combined panel markers including CK20, CDX2, FGFR1, VEGF, and IGF-1 or CK20, CDX2, FGFR1, and VEGF, also can be good prognostic markers.

\section{Conclusions}

In this study, we identified fibrosis and FGFR1 expression as new prognostic markers to predict tumor recurrence and overall survival, respectively. Moreover, there was no significant correlation between stem cell markers and overall survival. Further basic studies on the VEGF and FGFR1 expression and the relationship between the markers need to be investigated in relation to EMT of PACs.

\section{Supplementary information}

Supplementary information accompanies this paper at https://doi.org/10. 1186/s12885-020-6673-2.

Additional file 1: Table S1. Comparison of T stage in AJCC cancer staging system 7th edition (2010) according to the tumor location. Table S2. Cox regression analysis for overall survival of periampullary/pancreatic cancer patients.

Additional file 2: Figure S1. Representative images of the immunohistochemical stainings using the tissue microarray of periampullary/ periampullary cancers $(\times 400)$. (a) Sox2 cytoplasm and nucleus (b) CD24 (c) OCT4 (d) IGF-1 (e) FGFR1, (f) VEGF (g) CD44v6 (h) CK7 (i) CK20 (j) CDX-2 (k) MUC2, with negative (no expression), 1+ (low expression), $2+$ (moderate expression) and $3+$ (high expression) intensity. Figure S2. Kaplan-Meier survival analysis on the relationship between disease free survival and clinical parameter in recurrent periampullary/ pancreatic cancers . There was significant difference according to (A) age, (C) location, (D) T stage, (F) Size, and (G) N stage. While there was no significant difference according to (B) sex, (E) gross type, and $(H) M$ stage. Figure S3. Kaplan-Meier survival analysis on the relationship between disease free survival and pathological parameter in recurrent periampullary/pancreatic cancers. There was significant difference according to (A) lymphatic invasion, (E) histological differentiation, (F) pancreatobillary type vs intestinal type, and $(G)$ fibrosis, while there was no significant relationship according to (B) vascular Invasion, (C) perineural invasion, (D) radial margin involvement, and $(H)$ inflammation. Figure S4. Kaplan-Meier survival analysis on the relationship between disease free survival analysis and expression level of the $\mathrm{IHC}$ markers in recurrent periampullary/pancreatic cancers. There was no significant difference according to (A) CK20, and (D) VEGF, while there was significant difference according to (B) CDX2, and (C) FGFR1. Figure S5. Cox regression analysis of FGFR in periampullary/pancreatic cancer patients. (A) Survival probability of FGFR1+, 2+, 3+ groups, (B) Log-Log survival probability of FGFRs $1+, 2+, 3+$ groups.

\section{Abbreviations}

AJCC: American Joint Cancer Committee; CT: Computed tomography; EMT: Epithelial-mesenchymal transition; FGFR1: Fibroblast growth factor receptor 1; IGF-1: Insulin-like growth factor-1; OCT-4: Octamer transcription factor-4; PET: Position emission tomography; PSC: Pancreatic stellate cells; TNM: Tumor, node, metastases; UICC: Union International Contre le Cancer staging system; VEGF: Vascular Endothelial growth factor

\section{Acknowledgments}

I appreciate Prof. T-J. Kim for advising on the conceptualization and funding acquisition and Mr. Y.D. Seo for reviewing the style.

\section{Authors' contributions}

YC conceptualized the study, acquired the funding, curated and analyzed the data, and write and edit the original and final draft. NT analyzed the data and write and edit the original and final draft. KYP curated the data and reviewed the final draft. EJL supervised the study, curated the data, and reviewed the final draft. CSK supervised the study, curated the data and reviewed the final draft. All authors have read and approved the final manuscript.

\section{Funding}

This study was supported by the Fukuoka Foundation for Sound Health Cancer Research Fund in 2014 at the design of the study.

\section{Availability of data and materials}

The original dataset of this study is available at http://www.researchgate.net/ profile/Yosep_Chong.

\section{Ethics approval and consent to participate}

This study was reviewed and approved by the Institutional Review Board of the Catholic University of Korea (SC14SISI0052) with a waiver of informed consent because the samples used in this study are legitimate according to the Bioethic Law and the data and images in this study were entirely deidentified. 


\section{Consent for publication}

Not applicable.

\section{Competing interests}

The authors declare that they have no competing interests.

\section{Author details}

'Department of Hospital Pathology, Yeouido St. Mary's Hospital, College of Medicine, The Catholic University of Korea, 10, 63-ro, Yeongdeungpo-gu, Seoul 07345, Republic of Korea. ${ }^{2}$ Department of Surgery, College of Medicine, The Catholic University of Korea, Seoul 07345, Republic of Korea. ${ }^{3}$ Department of Pathology, Shinwon Medical Foundation, Soha-ro 109 beon-gil, Gwanmyeong-si 14316, Gyeonggi-do, Republic of Korea. ${ }^{4}$ Department of Pathology, Samkwang Medical Laboratories, 57, Baumoe-ro 41-gil, Seocho-gu, Seoul 06742, Republic of Korea.

Received: 19 September 2019 Accepted: 24 February 2020 Published online: 14 March 2020

\section{References}

1. Rosai J, Ackerman LV, Rosai J. Rosai and Ackerman's surgical pathology, 10th edn. Edinburgh. New York: Mosby; 2011.

2. Adsay NV, Bagci P, Tajiri T, Oliva I, Ohike N, Balci S, Gonzalez RS, Basturk O, Jang KT, Roa JC. Pathologic staging of pancreatic, ampullary, biliary, and gallbladder cancers: pitfalls and practical limitations of the current AJCC/ UICC TNM staging system and opportunities for improvement. Semin Diagn Pathol. 2012;29(3):127-41.

3. Edge SB. American joint committee on Cancer: AJCC cancer staging manual, 7th edn. New York: Springer; 2010.

4. Herreros-Villanueva M, Zhang JS, Koenig A, Abel EV, Smyrk TC, Bamlet WR, de Narvajas AA, Gomez TS, Simeone DM, Bujanda L, et al. SOX2 promotes dedifferentiation and imparts stem cell-like features to pancreatic cancer cells. Oncogenesis. 2013;2:e61.

5. Lin H, Sun LH, Han W, He TY, Xu XJ, Cheng K, Geng C, Su LD, Wen H, Wang $X Y$, et al. Knockdown of OCT4 suppresses the growth and invasion of pancreatic cancer cells through inhibition of the AKT pathway. Mol Med Rep. 2014;10(3):1335-42.

6. Lu Y, Zhu H, Shan H, Lu J, Chang X, Li X, Lu J, Fan X, Zhu S, Wang Y, et al. Knockdown of Oct4 and Nanog expression inhibits the stemness of pancreatic cancer cells. Cancer Lett. 2013;340(1):113-23.

7. Herreros-Villanueva M, Bujanda L, Billadeau DD, Zhang JS. Embryonic stem cell factors and pancreatic cancer. World J Gastroenterol. 2014;20(9):2247-54.

8. Roche J. The Epithelial-to-Mesenchymal Transition in Cancer. Cancers (Basel). 2018:10(2).

9. Hubbard SR, Till JH. Protein tyrosine kinase structure and function. Annu Rev Biochem. 2000;69:373-98.

10. Jung DE, Kim JM, Kim C, Song SY. Embigin is overexpressed in pancreatic ductal adenocarcinoma and regulates cell motility through epithelial to mesenchymal transition via the TGF- pathway. Mol Carcinogen. 2016;55(5): 633-45.

11. Peng YP, Zhu Y, Yin LD, Wei JS, Liu XC, Zhu XL, Miao Y. PIK3R3 promotes metastasis of pancreatic Cancer via ZEB1 induced epithelial-Mesenchymal transition. Cell Physiol Biochem. 2018;46(5):1930-8.

12. Zhang S, Huang $X$, Tian $Y$, Aimaiti S, Zhang J, Zhao J, Chen Y, Wang C. Clinicopathologic characteristics, laboratory parameters, treatment protocols, and outcomes of pancreatic cancer: a retrospective cohort study of 1433 patients in China. PeerJ. 2018;6:e4893.

13. Pu D, Liu J, Li Z, Zhu J, Hou M. Fibroblast growth factor receptor 1 (FGFR1), partly related to vascular endothelial growth factor receptor 2 (VEGFR2) and microvessel density, is an independent prognostic factor for non-small cell lung Cancer. Med Sci Monit. 2017;23:247-57.

14. Brunello E, Brunelli M, Bogina G, Caliò A, Manfrin E, Nottegar A, Vergine M, Molino A, Bria E, Massari F, et al. FGFR-1 amplification in metastatic lymphnodal and haematogenous lobular breast carcinoma. J Exp Clin Cancer Res. 2012;31(1):103.

15. Weiss J, Sos ML, Seidel D, Peifer M, Zander T, Heuckmann JM, Ullrich RT, Menon R, Maier S, Soltermann A, et al. Frequent and Focal FGFR1 Amplification Associates with Therapeutically Tractable FGFR1 Dependency in Squamous Cell Lung Cancer. Sci Transl Med. 2010;2(62):62ra93.
16. Cancer Genome Atlas Research Network. Electronic address aadhe, Cancer genome atlas research $\mathrm{N}$ : integrated genomic characterization of pancreatic ductal adenocarcinoma. Cancer Cell. 2017;32(2):185-203 e113.

17. Chen B, Liu S, Gan L, Wang J, Hu B, Xu H, Tong R, Yang H, Cristina I, Xue J, et al. FGFR1 signaling potentiates tumor growth and predicts poor prognosis in esophageal squamous cell carcinoma patients. Cancer Biol Ther. 2018;19(1):76-86.

18. Seo AN, Jin Y, Lee HJ, Sun PL, Kim H, Jheon S, Kim K, Lee CT, Chung JH. FGFR1 amplification is associated with poor prognosis and smoking in nonsmall-cell lung cancer. Virchows Arch. 2014;465(5):547-58.

19. Haq F, Sung YN, Park I, Kayani MA, Yousuf F, Hong SM, Ahn SM. FGFR1 expression defines clinically distinct subtypes in pancreatic cancer. J Transl Med. 2018;16(1):374

20. Thomas D, Radhakrishnan P. Tumor-stromal crosstalk in pancreatic cancer and tissue fibrosis. Mol Cancer. 2019;18(1):14.

21. Ikuta D, Miyake T, Shimizu T, Sonoda H, Mukaisho K-I, Tokuda A, Ueki T, Sugihara $\mathrm{H}$, Tani M. Fibrosis in metastatic lymph nodes is clinically correlated to poor prognosis in colorectal cancer. Oncotarget. 2018;9(51): 29574-86.

22. Myoteri D, Dellaportas D, Lykoudis PM, Apostolopoulos A, Marinis A, ZiziSermpetzoglou A. Prognostic evaluation of Vimentin expression in correlation with Ki67 and CD44 in surgically resected pancreatic ductal adenocarcinoma. Gastroenterol Res Pract. 2017;2017:9207616.

23. Seo Y, Baba H, Fukuda T, Takashima M, Sugimachi K. High expression of vascular endothelial growth factor is associated with liver metastasis and a poor prognosis for patients with ductal pancreatic adenocarcinoma. Cancer. 2000;88(10):2239-45.

24. Wang Q, He W, Lu C, Wang Z, Wang J, Giercksky KE, Nesland JM, Suo Z. Oct3/4 and Sox2 are significantly associated with an unfavorable clinical outcome in human esophageal squamous cell carcinoma. Anticancer Res. 2009;29(4):1233-41.

25. Quint K, Tonigold M, Di Fazio P, Montalbano R, Lingelbach S, Ruckert F, Alinger B, Ocker M, Neureiter D. Pancreatic cancer cells surviving gemcitabine treatment express markers of stem cell differentiation and epithelial-mesenchymal transition. Int J Oncol. 2012;41(6):2093-102.

26. Quint K, Stintzing S, Alinger B, Hauser-Kronberger C, Dietze O, Gahr S, Hahn EG, Ocker M, Neureiter D. The expression pattern of PDX-1, SHH, patched and $\mathrm{Gli}-1$ is associated with pathological and clinical features in human pancreatic cancer. Pancreatology. 2009;9(1-2):116-26.

27. Amin MB, American Joint Committee on Cancer., American Cancer Society: AJCC cancer staging manual, Eight edition / editor-in-chief, Mahul B. Amin, MD, FCAP ; editors, Stephen B. Edge, MD, FACS and 16 others ; Donna M. Gress, RHIT, CTR - Technical editor ; Laura R. Meyer, CAPM - Managing editor. edn. Chicago: American Joint Committee on Cancer, Springer; 2017.

\section{Publisher's Note}

Springer Nature remains neutral with regard to jurisdictional claims in published maps and institutional affiliations.

Ready to submit your research? Choose BMC and benefit from:

- fast, convenient online submission

- thorough peer review by experienced researchers in your field

- rapid publication on acceptance

- support for research data, including large and complex data types

- gold Open Access which fosters wider collaboration and increased citations

- maximum visibility for your research: over $100 \mathrm{M}$ website views per year

At BMC, research is always in progress.

Learn more biomedcentral.com/submissions 